\title{
Lima: encierro y evasión en La ciudad y los perros de Mario Vargas Llosa
}

\author{
Edward MEDINA FRISANCHO \\ Departamento de Composición Arquitectónica \\ ETSAM / Universidad Politécnica de Madrid \\ edmedinaf@gmail.com
}

Recibido: 30/03/2012

Modificado: $16 / 05 / 2012$

Aceptado: $18 / 05 / 2012$

\section{Resumen}

A partir de la novela La ciudad y los perros de Mario Vargas Llosa se extraen aquellos elementos alegóricos y simbólicos, a fin de establecer una exégesis de la ciudad de Lima de mediados del siglo XX, cuya problemática urbanística perdura hasta nuestros días (2012).

Palabras clave: Lima, La ciudad y los perros, Mario Vargas Llosa, encierro y evasión.

Title: Lima: confinement and escape in The time of the hero by Mario Vargas Llosa

\section{Abstract}

From the novel The Time of the Hero by Mario Vargas Llosa are extracted those allegorical and symbolic elements, to establish an exegesis of the city of Lima in mid-twentieth century, as urban problems continues to this day (2012).

Keywords: Lima, The Time of the Hero, Mario Vargas Llosa, confinement and escape.

\section{Índice}

1. Introducción

2. "Matrioska" espacial en La ciudad y los perros

3. Ámbitos urbano-narrativos

4. Encierro y evasión en la ciudad de Lima

\section{Introducción}

La literatura como forma de representación de la ciudad constituye una fuente de enorme utilidad toda vez que es posible extrapolar juicios de valor semántico, a fin de completar el concepto de ciudad más allá de la univocidad del término y la metáfora. La ciudad de Lima, en ese sentido, ha sido escenario de una numerosa narrativa, como la del escritor peruano Mario Vargas Llosa quien en su primera novela La ciudad y los perros ${ }^{1}$ nos ofrece una visión compleja y

1 Manejaremos la primera edición de La ciudad y los perros publicada por Seix Barral (1963). 
representativa de la ciudad de Lima de los años 50 y que, dada su importancia y universalidad de conceptos, trasciende hasta nuestros días (2012).

A diferencia de la profusa crítica literaria realizada a la obra vargasllosiana, principalmente a La ciudad y los perros ${ }^{2}$, el presente artículo se inclina más hacia un ejercicio interpretativo de la novela dejando de lado todo análisis narrativo, tematológico o estilísticopara extraer algunas ideas en torno a la ciudad de Lima, expuestas en forma de alegorías y símbolos a lo largo del relato.

Desde el título La ciudad y los perros, el autor nos plantea una estructura a priori de dos elementos relacionados fuertemente entre sí mediante una conjunción copulativa, pero que por momentos parece enfrentarlos. Por un lado la ciudad de Lima que, a mediados del siglo pasado, sufría uno de los cambios más importantes de su evolución urbana: el de la explosión demográfica, la ingente migración de la sierra a la costa y el consecuente nacimiento de cinturones de pobreza de forma acelerada ${ }^{3}$. Esta es la Lima que el escritor peruano encuentra al llegar en 1947: emergente, mestiza, variopinta; con una afluencia de razas y estratos sociales que cambiarían completamente en las décadas siguientes la fisonomía de la ciudad de Lima y abrirían paso a la ciudad metropolitana.

Por otro lado, la de los "perros". Llamados así, peyorativamente, los cadetes que ingresan por primera vez en las aulas militares. El "perro" alude, en sentido lato, al individuo más bajo en la escala de valores de una sociedad civilizada. Representa al animal sin protección, huérfano de padre, que transita por las calles sin rumbo fijo. Es, además, el hombre deshumanizado que emerge de las sociedades fragmentadas y altamente polarizadas. El "perro" es el último eslabón del orden jerárquico, sometido siempre a otros individuos o entidades superiores y que carece, a su vez, de otro a quien someter. Para ello buscará ejercer dominio dentro de los de su misma especie. Así en La ciudad y los perros, después del "bautizo" de rigor, la sección de alumnos liderada por el temible Jaguar decide formar el "Círculo". Inicialmente, para combatir los abusos cometidos por los alumnos de cuarto año pero, más adelante, para ejercer autoridad sobre sus mismos compañeros, administrar la venta de alcohol y cigarrillos o planear el robo de uniformes y exámenes. Es,

2 Sobre la obra completa de Mario Vargas Llosa resaltan los estudios de José Miguel Oviedo, Mario Vargas Llosa, la invención de una realidad (1970) y José Luis Martín, La narrativa de Vargas Llosa. Acercamiento estilístico (1974). Sobre la novela en particular destacan César Camilo Ramírez, Análisis de La ciudad y los perros. Mario Vargas Llosa (2004); Carmen Rodríguez Moncada, Estudio literario: La ciudad y los perros, Mario Vargas Llosa (2001) y Peter Standish, Vargas Llosa, La ciudad y los perros (1982).

3 Sólo hacia 1940 la población estimada en Lima era de 600 mil habitantes. Hacia 1961 alcanzó 1,9 millones y 3,4 millones en 1972 (INEI 2007). 
precisamente, el robo del examen de Química el motor que desencadena el movimiento narrativo de la historia y lo que motivará la clausura de toda la sección de alumnos por parte de las autoridades militares. En ello detectamos una de las relaciones fundamentales en la obra: la de infracción-castigo. El encierro, como ejercicio disciplinario contra la infracción, sólo es posible mediante la existencia de una estructura confinada, materializada en una "gran arquitectura cerrada, compleja y jerarquizada" (Foucault 2002: 70) y cuyo elemento esencial de cerramiento es el muro:

El alto muro, no ya el que rodea y protege, no ya el que manifiesta, por su prestigio, el poder y la riqueza, sino el muro cuidadosamente cerrado, infranqueable en uno y otro sentido, y que encierra el trabajo ahora misterioso del castigo, será, próximo y a veces incluso en medio de las ciudades del siglo XIX, la figura monótona, a la vez material y simbólica, del poder de castigar. (Foucault 2002: 70)

Como veremos más adelante en la novela, la vulneración y privación de la libertad conducirá inexorablemente a los inculpados a la elección de dos caminos divergentes: la traición o la acción evasiva.

\section{2. "Matrioska" espacial en La ciudad y los perros}

En La ciudad y los perros asistimos a lo que podríamos llamar una "matrioska" espacial o juego de "muñecas rusas" a nivel urbano, debido a la construcción de ámbitos espaciales dentro de otros mayores, a modo de círculos concéntricos (vid. figura 1). Esta construcción de escenarios que va desde la cuadra, el colegio militar hasta llegar a la ciudad, dan lugar a tres espacios urbano-narrativos, cuyo rasgo común es la condición de "cerramiento" (el número de espacios se incrementa si consideramos, por un lado, la celda donde es encerrado el Jaguar $y$, por otro, el territorio o país de donde finalmente emigra el Poeta).

Los personajes viven inmersos en ese orden de confinamiento, al cual acceden sin elección. Sin embargo buscan evadirlo a toda costa, agobiados por la severa verticalidad social y militar, visible, además, mediante unos límites físicos impuestos por la propia arquitectura. 


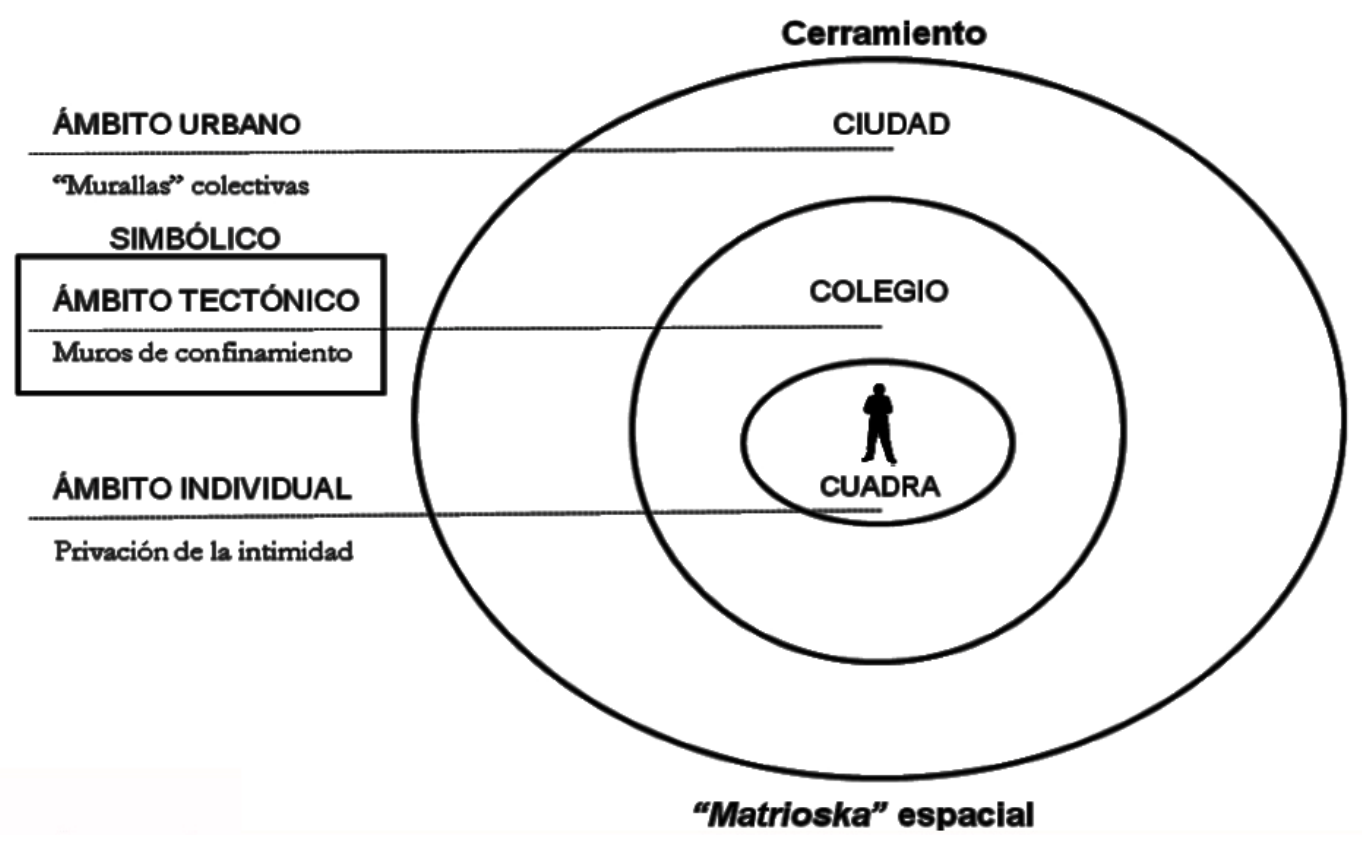

Fuente: Elaboración propia.

Figura 1. "Matrioska" espacial o disposición de espacios construidos dentro de otros en La ciudad y los perros.

\section{3. Ámbitos urbano-narrativos}

Los tres ámbitos espaciales mencionados, por orden ascendente, son los siguientes:

a) Ámbito individual: El dormitorio como lugar unipersonal es la unidad mínima e indivisible y cuya intimidad, en la novela, es vulnerada íntegramente al configurarse como un espacio colectivo: la cuadra. Diseñada como un "recinto estirado y alto" dividido por un pasillo central en el cual pernoctan los cadetes "entre dos columnas de literas" (Vargas Llosa 1963: 8) ${ }^{4}$, en la cuadra la privación de la libertad individual se hace patente y se diluye en la conformación de la conciencia de grupo.

b) Ámbito tectónico: el del Colegio Militar Leoncio Prado donde transcurre la mayor parte de la narración y que deviene en el mundo novelesco y el espacio simbólico por excelencia. Cerrado, introspectivo, austero, en el colegio militar confluyen todas las figuras metafóricas y metonímicas que dan relieve a la obra: el muro, el descampado, la niebla, la pista de desfile, la celda, la noche, el mar invisible, la alameda, son siempre vehículos de significación de un orden mayor.

El Colegio Militar Leoncio Prado, como lo han anotado varios autores, representa a una "sociedad jerárquica e injusta" (Williams

${ }^{4}$ En adelante, en las citas referidas a esta edición de La ciudad y los perros, sólo se indicará el número de página. 
2000: 6), "microcosmos de la sociedad peruana" (Martín 1974: 86); pero también, y ateniéndose con mayor precisión al título de la obra, es una representación alegórica y a menor escala del ámbito completo de la ciudad de Lima. Aquella también nos remite, en su rostro más áspero, a la violencia de la urbe, a su imposibilidad de conformar un locus amoenus.

El Colegio Militar no podía tener una ubicación más paradójica. Junto al acantilado del mar de la Perla, en el Callao, el conjunto de forma alargada se emplaza paralelamente al litoral, no obstante cercado por sus muros perimetrales. El mar, desde el internado, se escucha, se huele, se siente, pero difícilmente puede ser visto. "El estallido de las olas y la resaca del mar extendido al pie del colegio, al fondo de los acantilados, apagaba el ruido de los botines" (4).

Asimismo, el colegio presenta aquellas características a las que Foucault había aludido en referencia a los ambientes carcelarios: cerramiento, complejidad y jerarquía, se reproducen magistralmente para configurar el recinto educativo-militar. Éstos tienen su plasmación física en el muro como elemento indispensable de confinamiento, el urbanismo a breve escala y la imponencia de los edificios de valor institucional. El resultado: una serie de espacios propedéuticos para la vida adulta, una ciudadela o "antesala" para la gran ciudad.

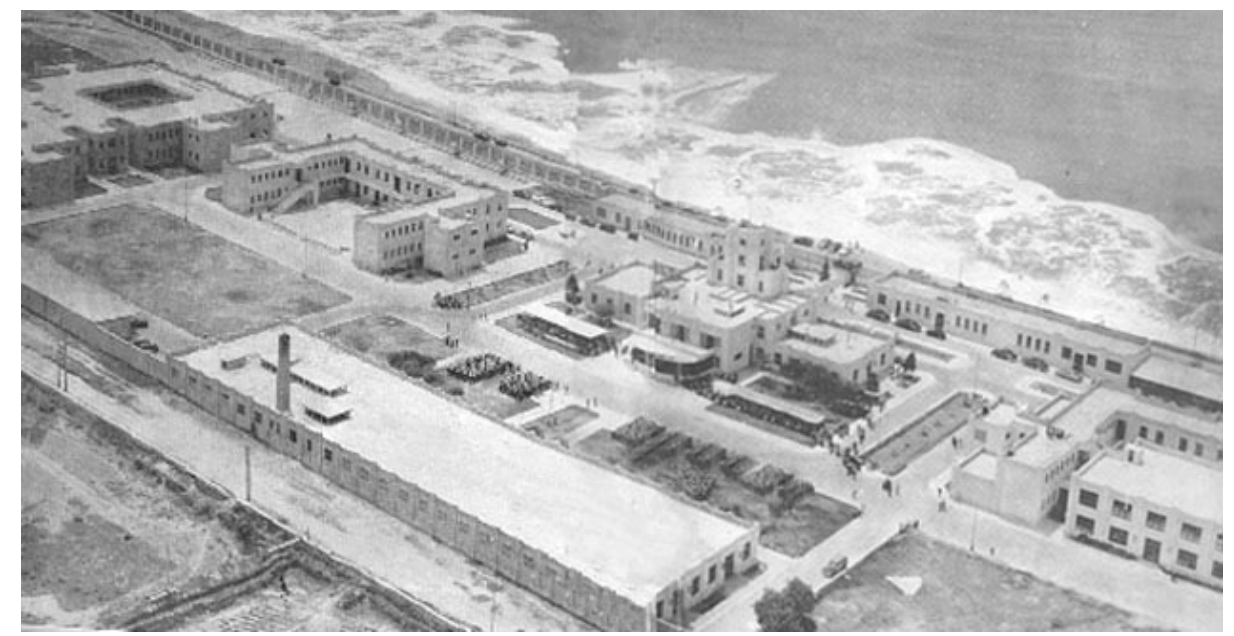

Figura 2. Vista aérea del colegio militar Leoncio Prado de los años 50. Nótese su extensión y relación con el mar.

c) Ámbito urbano: La ciudad de Lima como objeto de deseo, como lugar al cual aspiran llegar los distintos personajes de la novela (el Poeta, el Jaguar, el Esclavo), es también el lugar en el cual esperan encontrar las claves de un destino individual, expulsados por la violencia y el encierro. Cada uno tentará a su modo su propia búsqueda y experiencia en las calles. Así, mientras que el Jaguar escapa de la policía, el Poeta inicia el camino hacia Huatica, en busca de la Pies Dorados, la musa del sexo. El encuentro con la ciudad por 
parte de los personajes será el encuentro con la inocencia perdida, tempranamente arrebatada. ¿Pero cómo se da en la realidad este encuentro entre hombre y ciudad? Según Rocío Peñalta: "La mejor manera de leer la ciudad, y en este punto coinciden todos los autores estudiados, consiste en recorrerla" (Peñalta 2010: 14). En efecto, el diálogo sordo que entablan los "perros" con la ciudad se da de manera inequívoca a través del recorrido, experiencia sensorial del espacio urbano.

A medida que avanzaba por 28 de Julio, la avenida se poblaba. Después de cruzar los rieles del tranvía Lima-Chorrillos, se halló en medio de una muchedumbre de obreros y sirvientas, mestizos de pelos lacios, zambos que cimbreaban al andar como bailando, indios cobrizos, cholos risueños. Pero él sabía que estaba en el distrito de la Victoria por el olor a comida y bebida criollas que impregnaba el aire, un olor casi visible a chicharrones y a pisco, a butifarras y a transpiración, a cerveza y pies. [...] La aglomeración lo obligaba a andar despacio; se asfixiaba. Las luces de la avenida parecían deliberadamente tenues y dispersas para acentuar los perfiles siniestros de los hombres que caminaban metiendo las narices en las ventanas de las casitas idénticas, alineadas a lo largo de las aceras. (90)

Sanabria Vega determina, por otro lado, cómo la jerarquía del poder, de la misma forma en que divide a la sociedad en dominadores y dominados, termina por sesgar igualmente a la ciudad, conformando barrios de las mismas características: Así, se tiene a) Miraflores: como el barrio que ostenta el poder del dinero, b) Lince y La Victoria: como el del poder de la fuerza y la violencia y c) El Leoncio Prado: como 'hogar' del Círculo (Sanabria 2011).

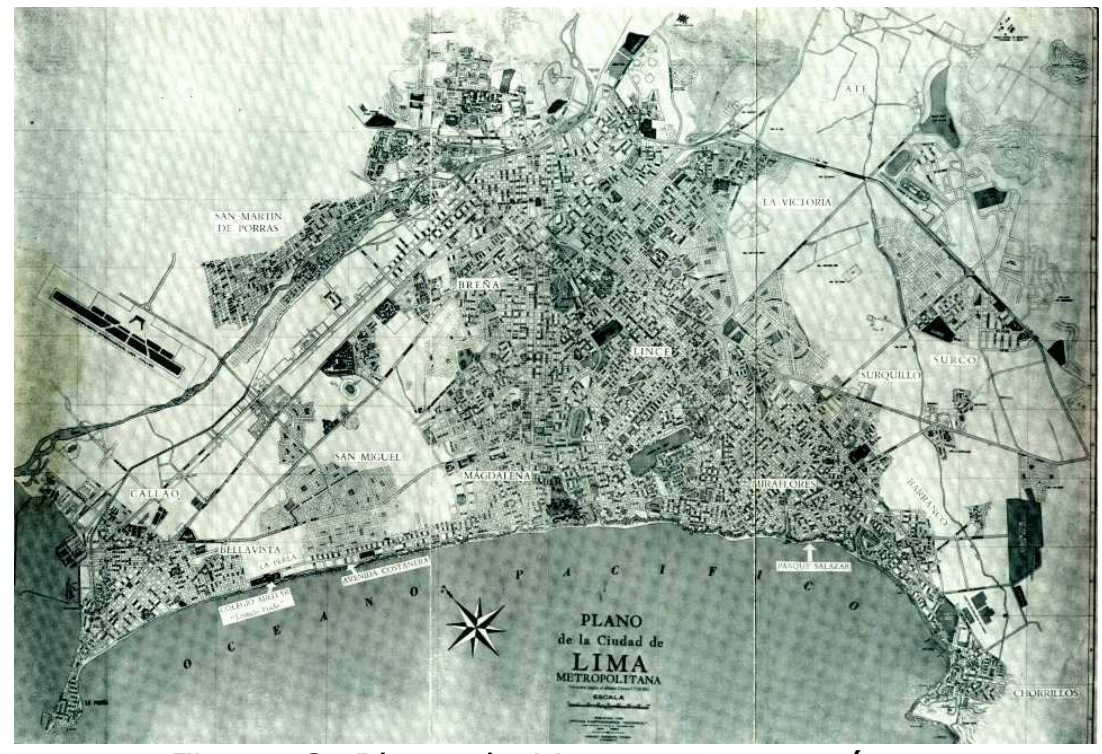

Figura 3. Plano de Lima que aparecía en las primeras ediciones de Seix Barral (1963). 


\section{Encierro y evasión en la ciudad de Lima}

Partiendo de la idea -ya delineada previamente- del Colegio Militar como representación alegórica de la ciudad de Lima, podemos identificar dentro de la novela hasta tres momentos claves durante el proceso de "encerramiento" del individuo, que extrapolamos con miras hacia una posible exégesis de la ciudad.

\section{a) Primera etapa: Acceso}

-Cuatro- dijo el Jaguar.

Los rostros se suavizaron en el resplandor vacilante que el globo de luz difundía por el recinto, a través de escasas partículas limpias de vidrio: el peligro había desaparecido para todos, salvo para Porfirio Cava. Los dados estaban quietos, marcaban tres y uno, su blancura contrastaba con el suelo sucio. (7)

Al igual que los personajes del colegio militar, el individuo se encuentra de pronto existiendo dentro de la ciudad, como "arrojado" a ella. Vale decir que acceden a ésta sin elección -en su mayoría por decisión de otros- y deben asimilar al trote su realidad en el mundo. Esta tesis de corte existencialista revela nuestra verdadera condición de ciudadanos. En La ciudad y los perros esta idea parece estar reforzada por una narración in media res, en la que el lector debe familiarizarse rápidamente con la narración de los hechos, como quien irrumpe en medio de una conversación de amigos.

b) Segunda etapa: Encierro

Podía soportar la soledad y las humillaciones que conocía desde niño y sólo herían su espíritu: lo horrible era el encierro, esa gran soledad exterior que no elegía, que alguien le arrojaba encima como una camisa de fuerza. (115)

El muro es el límite del mundo. Establece hasta dónde podemos llegar como víctimas del encierro. "Al otro lado del estadio, después de una construcción ruinosa -el galpón de los soldados- hay un muro grisáceo donde acaba el mundo del Colegio Militar Leoncio Prado y comienzan los grandes descampados de La Perla" (16).

El encierro es el correlato moral frente al delito. A diferencia de éste último, el encierro es siempre colectivo. El encierro produce hombres "animalizados", arrancados de su propia humanidad. De esa manera, el individuo tiene sólo dos salidas posibles frente al encierro existente, el de la traición -que como ya sabemos, en el caso del Esclavo, conlleva la muerte- o el ejercicio de la evasión.

c) Tercera etapa: Evasión

[...] no descubren nunca lo que pasa en las cuadras si nosotros no queremos, mi teniente. Y él no era como los demás, no se atrevía a tirar contra. 
- ¿Contra?

-Todos tiran contra, hasta los perros. (241)

Los individuos buscan evadir la realidad que la ciudad impone. Esa es su condición natural. Lo hacen "tirando contra" (trepando el muro) a la estructura que los confina. Este sencillo acto simboliza la más significativa acción transgresora, porque se hace precisamente a riesgo de ser sujeto de castigo e, incluso, como sucede con los cadetes del quinto año, ignorando que esta empresa los lleve eventualmente al fracaso. Alonso Cueto, en su ensayo El fuego transgresor, resume rotundamente esta idea:

Como él [Mario Vargas Llosa], sus personajes se sienten bien cuando están al aire libre. A lo largo de su obra, hay grandes escenas en exteriores; [...]. El confinamiento físico es una señal perversa para sus personajes. Su primera gran novela La ciudad y los perros empieza en un interior sombrío (bajo el "resplandor vacilante" de un "globo de luz") y su relato es el de los sueños de los cadetes por salir del encierro. Luego descubrirán que la ciudad (y el destino que tienen en ella) es también una prisión. (Cueto 2007)

¿Pero en qué consiste esta condición de cerramiento de la ciudad a la que hemos hecho tanta referencia? Foucault indicaba que una de las formas primarias de encierro, el calabozo, cumplía, al menos, tres condiciones necesarias para el castigo: la soledad, la oscuridad y la restricción de alimentos (Foucault 2002: 71). Podríamos afirmar entonces, sin ir muy lejos, que estas mismas condiciones se repiten a mayor escala en nuestras ciudades contemporáneas. La incomunicación, la negación de los espacios públicos, la ausencia de áreas naturales, la tugurización y la pobreza, son nuestras nuevas formas de castigo. Las ciudades que habitamos son nuestras cárceles de hoy en día.

La evasión o apertura de la ciudad de Lima no radica sino en la amplitud de su perspectiva, en la creación de espacios comunes y dinámicos, exenta de las "murallas" que la aíslan colectivamente. Nuevamente los espacios abiertos: la vereda, la calle, la plaza, el parque, el río y -principalmente- el mar, como paradigma del espacio ilimitado, son nuestra única salida física frente al confinamiento.

El autor nos presenta en La ciudad y los perros la cara más áspera de la ciudad limeña del siglo XX -acaso de una realidad latinoamericana- signada por la soledad y el encierro. En dicha obra, somos testigos de la ausencia del ideal de ciudad reemplazada por la cruenta imagen de una ciudad "amurallada". Una imagen que no se aleja de la realidad que habitan actualmente los ciudadanos. Dependerá de una real comprensión del problema y de la ejecución de ciertas políticas para cambiar este imaginario de reclusión por uno más abierto e inclusivo. 


\section{Bibliografía}

CUETO, Alonso (2007): "El fuego transgresor. Las claves de la narrativa de Vargas Llosa" [en línea]. El Comercio. Suplemento El Dominical, 24 de junio. En: http://elcomercio.pe/edicionimpresa/html/2007-0623/ImEcDominical0743849.html [Consulta: 05/01/2012].

FOUCAULT, Michel (2002): Vigilar y castigar: nacimiento de la prisión. Primera edición. Buenos Aires: Siglo XXI editores.

INSTITUTO NACIONAL DE ESTADÍSTICA E INFORMÁTICA (2007): Perfil sociodemográfico de Perú. Lima: INEI. En: http://www.inei.gob.pe/Anexos/libro.pdf [Consulta: 30/04/2011].

MARTÍN, José Luis (1974): La narrativa de Vargas Llosa. Acercamiento estilístico. Madrid: Gredos.

OVIEDO, José Miguel (1970): Mario Vargas Llosa: la invención de una realidad. Barcelona: Barral editores.

PEÑALTA CATALÁN, Rocío (2010): "El espacio urbano: de la metáfora a la significación. Una aproximación teórica", en Eugenia Popeanga (coord.), Ciudad en obras. Metáforas de lo urbano en la Literatura y en las Artes, pp. 11-22. Berna: Peter Lang.

RAMÍREZ, César Camilo (2004): Análisis de La ciudad y los perros. Mario Vargas Llosa. Bogotá: Panamericana Editorial.

RODRÍGUEZ MONCADA, Carmen (2001): Estudio literario: La ciudad y los perros, Mario Vargas Llosa. Bogotá: Panamericana Editorial.

SANABRIA, Ludy (2011): "Los impostores del poder en La ciudad y los perros de Mario Vargas Llosa" [en línea]. Espéculo. Revista digital de estudios literarios.

En: http://www.ucm.es/info/especulo/numero47/ciuperro.html [Consulta: 05/01/2012].

STANDISH, Peter (1982): Vargas Llosa, La ciudad y los perros. Londres: Grant \& Cutler-Tamesis Books.

VARGAS LLOSA, Mario (1963): La ciudad y los perros. Barcelona: Seix Barral.

WILLIAMS, L. Raymond (2000): "Los primeros demonios. La ciudad y los perros". Los universitarios. Nueva Época (UNAM), núm. 2, pp. 4-7. 